\title{
Editorial
}

\section{Rising trend to Caesarean Section in Bangladesh: An Upcoming Health Hazards to Women}

\begin{abstract}
Caesarean section (CS) is an operative procedure whereby the fetus/fetuses after the end of $28^{\text {th }}$ week are delivered through an incision on the anterior abdominal and uterine walls. It is done when vaginal delivery is not possible and the life of mother or babies are in jeopardy. It is well known that, hemorrhage, obstructed and prolonged labor contribute to major causes of maternal mortality and morbidity in Bangladesh (BD). Maternal mortality ratio is a good indicator of the health status of the women of a country. In 1990, MMR in BD was 574/ 100000 live births. In MDG-5, the goal was to reduce maternal mortality to $143 / 100000$ live births by 2015 i.e. $75 \%$ reduction in maternal mortality and $50 \%$ child birth by skill birth attendant.
\end{abstract}

SR Das

Efforts to reduce maternal mortality became a matter of high priority to the nation from late 1990s and the Government of Bangladesh and UNICEF initiated the emergency obstetrics care (EOC) program to achieve the goal. EOC training programs were conducted to develop skilled personnel in anesthesia and obstetrics to tackle the emergency situations. Facilities were also extended to different health facilities phase by phase. Currently EOC program is running in all public Medical College Hospitals (MCH), District Hospitals (DH), Upazila Health Complexes and MCWC. A good number of private clinics, hospitals and NGO providers are also participating in this program. As a result, over the last few years Bangladesh has made significant progress in improvement of maternal health. Though we could not achieve the goal set by WHO but we are in the track. There has been $40 \%$ reduction in maternal mortality between the years 2001 to 2010 . All types of deliveries in health facilities have increased from $4 \%$ to 15\% from 1993 to 2007 (BDHS 2007).

Preliminary results of BDHS (source: bdnews24.com, 26/ 04/2015) has reported that the rate of Caesarean Section was $23 \%$ in 2014 whereas it was only $4 \%$ in 2004, $9 \%$ in 2007 and $17 \%$ in 2011. WHO recommended acceptable limit is $10 \%$ to $15 \%$. So it is $6 \%$ higher from 2011 and 8\% higher than WHOs' maximum prescribed limit. Among total deliveries, $37 \%$ births have occurred in both government and non-

Dr. Shila Rani Das, FCPS (Gynae and Obs), Professor \& Head, Dept. of Obstetrics \& Gynecology, Faridpur Medical College, Faridpur.

Address of correspondence :

Dr. Shila Rani Das, FCPS (Gynae and Obs), Professor \& Head, Dept. of Obstetrics \& Gynecology, Faridpur Medical College, Faridpur.Mobile: +88-01712288609,

Email: shilaranidas@yahoo.com government health facilities, of which $22 \%$ are at private facilities. Not only had that $80 \%$ was CS performed in private sectors. We are really happy that, the current maternal mortality ratio is around $170 / 100000$ live births, at the same time we are also worried about the increasing rate of CS not only in Bangladesh but also globally. A study by WHO in 2007 found that when the Caesarean section rate of a country goes above $15 \%$, the maternal mortality rises, i.e. unnecessary CS kills women, increases the risk of maternal morbidity, neonatal death and neonatal admission to an intensive care unit. Caesarean delivery rates among the women in the richest quintile were much higher than the rates seen in the poorest quintile. This difference was particularly noticeable in Bangladesh, India and Pakistan, where the poorest quintile probably receives fewer caesarean sections than are indicated, while the richest quintile receives too many - increasing maternal and neonatal morbidity. Besides the solvency, increasing number of health facilities of public, private and NGOs in different levels of the country, trained EOC providers, small family norms, lack of patience and confidence for vaginal delivery of some women, improper assessment of patient for CS are the factors for unnecessary Caesarean section. In periphery, there are so many clinics running without sufficient skilled manpower and with substandard operative theatre facilities. 